\title{
Epidemiología del SARS-CoV-2
}

\section{Epidemiology SARS-CoV-2}

\author{
Martha Soledad Ramiro-Mendoza
}

Resumen

Un nuevo coronavirus, que causa el síndrome respiratorio agudo severo coronavirus 2 (SARS-CoV-2), surgió en China y se ha disparado en todo el mundo creando una pandemia. A finales de 2019 se detectaron e informaron varios casos de neumonía atípica de etiología desconocida, inicialmente en Wuhan, provincia de Hubei, China. Poco después, el Centro Chino para el Control y Prevención de Enfermedades identificó como agente causal al nuevo coronavirus de una muestra de hisopo de la garganta de un paciente y lo anunció, oficialmente, el 7 de enero de 2020. El virus se propagó rápidamente a más de 150 países. Entre el 31 de diciembre de 2019 y el 28 de febrero de 2020 se habían confirmado en el laboratorio 83,631 casos de COVID-19, y 2858 muertes.

La superación de esta pandemia dependerá, en su mayor parte, de la disciplina que la población mundial tenga para respetar las reglas de convivencia, el distanciamiento social y, la única y mejor medida de prevención de casos en futuras temporadas, será mantener la guardia y no dejar de aplicar las medidas de prevención sugeridas.

PALABRAS CLAVE: Nuevo coronavirus; SARS CoV 2; pandemia; neumonía atípica; COVID 19; temporadas; influenza humana.

Abstract

A novel coronavirus causing severe acute respiratyory syndrome coronavirus 2 (SARSCoV-2) emerged in China and has spred globally, creating a worldwide pandemic. At the end of 2019, several cases of atypical pneumonia of unknown a etiology, were initially detected and reported in Wuhan, Hubei province, China. Shortly afterwards, the Chinese Center for Disease Control and Prevention (CDC) identified the novel coronavirus from the throat swab sample of a patient as the causative agent, and officially announced it on 7 January 2020. The virus spread rapidly to more than 150 countries, between december 31, 2019 and February 28, 2020, 83,631 laboratory-confirmed cases of COVID-19, including 2,858 deaths.

Overcoming this pandemic will depend a greater extent on the discipline that the world population has to respect the rules of coexistence / social distancing and the only and best measure to prevent cases in future seasons will be to keep guard and not stop applying suggested prevention measures.

KEYWORDS: Novel Coronavirus; SARS CoV 2; Pandemic; Atypical Pneumonia; COVID 19; Seasons; Influenza, Human.
Jefa del servicio de Epidemiología.

Instituto Nacional de Pediatría, Ciudad de México.

Recibido: 12 de mayo 2020

Aceptado: 15 de junio 2020

Correspondencia Martha Soledad Ramiro-Mendoza marchs1764@hotmail.com

Este artículo debe citarse como Ramiro-Mendoza MS. Epidemiología del SARS-CoV-2. Acta Pediatr Méx 2020; 41 (Supl 1):S8-S14.

\section{El inicio de la pandemia}

El 31 de diciembre de 2019, la Comisión Municipal de Salud de Wuhan (provincia de Hubei, China) notificó un conglomerado de casos de neumonía en la ciudad; posteriormente, se determinó que eran causados por un nuevo coronavirus. Ante esta situación, el 1 de enero de 2020, la OMS estableció el correspondiente
Equipo de Apoyo a la Gestión de Incidentes en los tres niveles de la Organización: la Sede, las sedes regionales y los países, y puso así a la Organización en estado de emergencia para abordar el brote. El 4 de enero dio a conocer, a través de redes sociales, la existencia de un conglomerado de casos de neumonía (sin fallecimientos) en Wuhan. El 10 de enero publicó una serie de orientaciones técnicas, con recomenda- 
ciones para todos los países, acerca del modo de detectar casos, realizar pruebas de laboratorio y tratar los posibles casos. ${ }^{1}$ Las orientaciones se basan en los conocimientos del virus existentes hasta ese momento y se remiten a los directores regionales de la OMS para emergencias, a fin de que las distribuyan entre los representantes de la OMS en los países. El 12 de enero de 2020 China hizo pública la secuencia genética del virus causante de la COVID-19.

El 13 de enero de 2020 se confirmó, oficialmente, el primer caso registrado fuera de China, en Tailandia. El 14 de enero de 2020 la responsable técnica de la OMS reportó la transmisión limitada del coronavirus entre seres humanos, fundamentalmente a través de familiares, y el riesgo de un posible brote más amplio. Fue hasta el 22 de enero de 2020 cuando la misión de la OMS a China emitió una declaración en la que afirmó que se había demostrado la transmisión entre seres humanos en Wuhan. El 16 de enero de 2020 las autoridades japonesas confirmaron el primer caso en Japón, en un ciudadano con antecedente de viaje a Wuhan, seguido de la confirmación del primer caso en suelo estadounidense el 21 de enero.

El 30 de enero de 2020 el Comité de Emergencias recomendó al Director General de la OMS que el brote constituyera una emergencia de salud pública de importancia internacional (ESPII). El Director General aceptó la recomendación y declaró que el brote por el nuevo coronavirus (2019-nCov) constituía una ESPII. Para ese momento, el informe de situación de la OMS señalaba la existencia de 7818 casos confirmados en todo el mundo, la mayoría de ellos en China y 82 en otros 18 países. ${ }^{2}$ Hasta ese momento las defunciones se registraban solo en China, pero el 2 de febrero de 2020 se confirmó la primera muerte fuera de China en un hombre de Filipinas.
Entre el 31 de diciembre de 2019 y el 28 de febrero de 2020 se habían notificado 83,631 casos confirmados por laboratorio de COVID-19, incluidas 2858 muertes, en 51 países. La mayoría de los casos (94\%) y muertes (98\%) se registraban en y dentro de China, en la provincia de Hubei se registraba la mayoría de los casos (83\%) y muertes (96\%). La cantidad de casos reportados en China y, potencialmente en otros países, quizá mostraba una subestimación, considerando la capacidad de las pruebas diagnósticas y los criterios y el alcance de la definición de caso, junto con la aparición de casos leves y asintomáticos.

Ante el crecimiento en la incidencia, el 11 de marzo de 2020 la OMS determinó, en su evaluación, que la situación originada por COVID-19 podía caracterizarse como pandemia. ${ }^{3}$

\section{Epidemiología de la región de las américas,} primeros casos confirmados

Estados Unidos de América. El primer caso confirmado de COVID-19 en Estados Unidos se informó el 21 de enero de 2020. Desde entonces y hasta finales de febrero se habían reportado 459 personas en investigación (PUI, por sus siglas en inglés) que fueron detectadas y diagnosticadas en Estados Unidos, incluidos 15 casos confirmados en 6 estados (Arizona, California, Illinois, Massachusetts, Washington y Wisconsin). De los 15 casos confirmados, 12 estaban relacionados con viajes y 3 ocurrieron por transmisión de persona a persona. Uno de esos casos, en el estado de California, no tenía una fuente conocida de infección o contacto con un caso conocido de COVID-19, lo que indicaba una posible diseminación en la comunidad. Además, había 3 personas repatriadas desde Wuhan, China, y 44 personas repatriadas desde el Crucero Diamond Princess, que resultaron positivas para COVID-19. 
Canadá. El primer caso confirmado en Canadá se informó el 25 de enero de 2020. Hasta finales de febrero se habían notificado 15 casos confirmados de COVID-19 (incluido un caso probable de confirmación), en las provincias de Ontario (7), Columbia Británica (7), y Quebec (1). Entre los casos confirmados, el sitio de transmisión en 2 casos estaba en investigación, 2 se debieron a la transmisión de persona a persona entre contactos cercanos de casos confirmados, 3 estuvieron expuestos en Irán y los 8 restantes tenían antecedentes de viaje a China. Ninguna de las personas repatriadas de Wuhan o el crucero Diamond Princess había dado positivo a las pruebas de laboratorio una vez que llegaron a Canadá.

Brasil. El primer caso confirmado en Brasil se informó el 26 de febrero de 2020. Este caso correspondió a un hombre de 61 años, residente de São Paulo, con antecedentes de viajes a la región de Lombardía en Italia y que tenía síntomas leves. El caso no informó contacto conocido con un caso sospechoso de COVID-19. Además, según el Ministerio de Salud de Brasil hasta finales de febrero se registraban 182 casos sospechosos, en 16 unidades federales.

México. Los primeros casos confirmados en México se informaron el 28 de febrero de 2020: un caso en la Ciudad de México y el otro en el estado de Sinaloa. Ambos casos tenían antecedentes de viaje a la región de Lombardía en Italia antes del inicio de los síntomas. ${ }^{3}$

\section{Panorama epidemiológico durante los primeros cinco meses tras el inicio de la pandemia}

A inicios del quinto mes, luego de notificarse el primer caso positivo, en el mundo se habían reportado 3,935,828 casos confirmados de SARS-CoV-2 y 274,655 defunciones, con una tasa de letalidad global de $6.9 \%$. Figuras 1 y 2
Hasta ese momento epidemiológico se habían reportado casos en 214 países, territorios y áreas; los casos se habían notificado en las seis regiones de la OMS (América, Europa, Asia Sudoriental, Mediterráneo Oriental, Pacífico Occidental y África).

En México hasta ese momento se reportaban 31,522 casos confirmados y 3160 defunciones por COVID-19. Las entidades federativas con mayor prevalencia de casos eran:

- CDMX. 8705 confirmados, 729 defunciones, 4987 sospechosos y 13,875 negativos.

- Estado de México. 5418 confirmados, 300 defunciones, 6340 sospechosos y 6758 negativos.

- Baja California. 2276 confirmados, 365 defunciones, 780 sospechosos y 1646 negativos.

- Tabasco. 1531 confirmados, 201 defunciones, 396 sospechosos y 1634 negativos.

- Sinaloa. 1372 confirmados, 204 defunciones, 657 sospechosos y 1612 negativos.

- Veracruz. 1049 confirmados, 112 defunciones, 651 sospechosos y 2043 negativos. Figuras 3,4

Definiciones operacionales para la identificación de casos

Para la identificación de casos de COVID-19, y dados los orígenes de dicha enfermedad, en un inicio se planteó la siguiente definición operacional:

Caso sospechoso: persona de cualquier edad que, en los últimos 14 días haya tenido fiebre o tos $y$, al menos, uno de los siguientes signos y síntomas: disnea, mialgias, cefalea, artralgias, u odinofagia. Y que, además, en el mismo periodo haya referido: a) haber estado en contacto 


\begin{tabular}{|c|c|c|c|c|}
\hline Ubicación & Casos confirmados & Casos por 1 mill. de personas & Curados & Fallecidos \\
\hline 由 Todo el mundo & 3.935 .828 & 506,16 & 1.319 .306 & 274.655 \\
\hline Estados Unidos & 1.317 .175 & $3.996,81$ & 182.305 & 78.198 \\
\hline España & 222.857 & $4.731,53$ & 131.148 & 26.299 \\
\hline Italia & 217.185 & $3.605,12$ & 99.023 & 30.201 \\
\hline Reino Unido & 211.364 & $3.181,49$ & - & 31.241 \\
\hline Rusia & 187.859 & $1.280,17$ & 26.608 & 1.723 \\
\hline Alemania & 170.588 & $2.051,59$ & 138.214 & 7.510 \\
\hline Brasil & 145.892 & 690,33 & 55.350 & 9.992 \\
\hline Francia & 138.421 & $2.063,64$ & 55.782 & 26.230 \\
\hline c. Turquía & 135.569 & $1.630,32$ & 86.396 & 3.689 \\
\hline T Irán & 104.691 & $1.256,33$ & 83.837 & 6.541 \\
\hline $\begin{array}{l}\text { República Popular } \\
\text { China }\end{array}$ & 82.887 & 59,12 & 78.046 & 4.633 \\
\hline
\end{tabular}

Figura1. Países con prevalencia más alta de COVID-19.

Fuente: https://google.com/coronavirus-map/?hl=es\&nv3=true

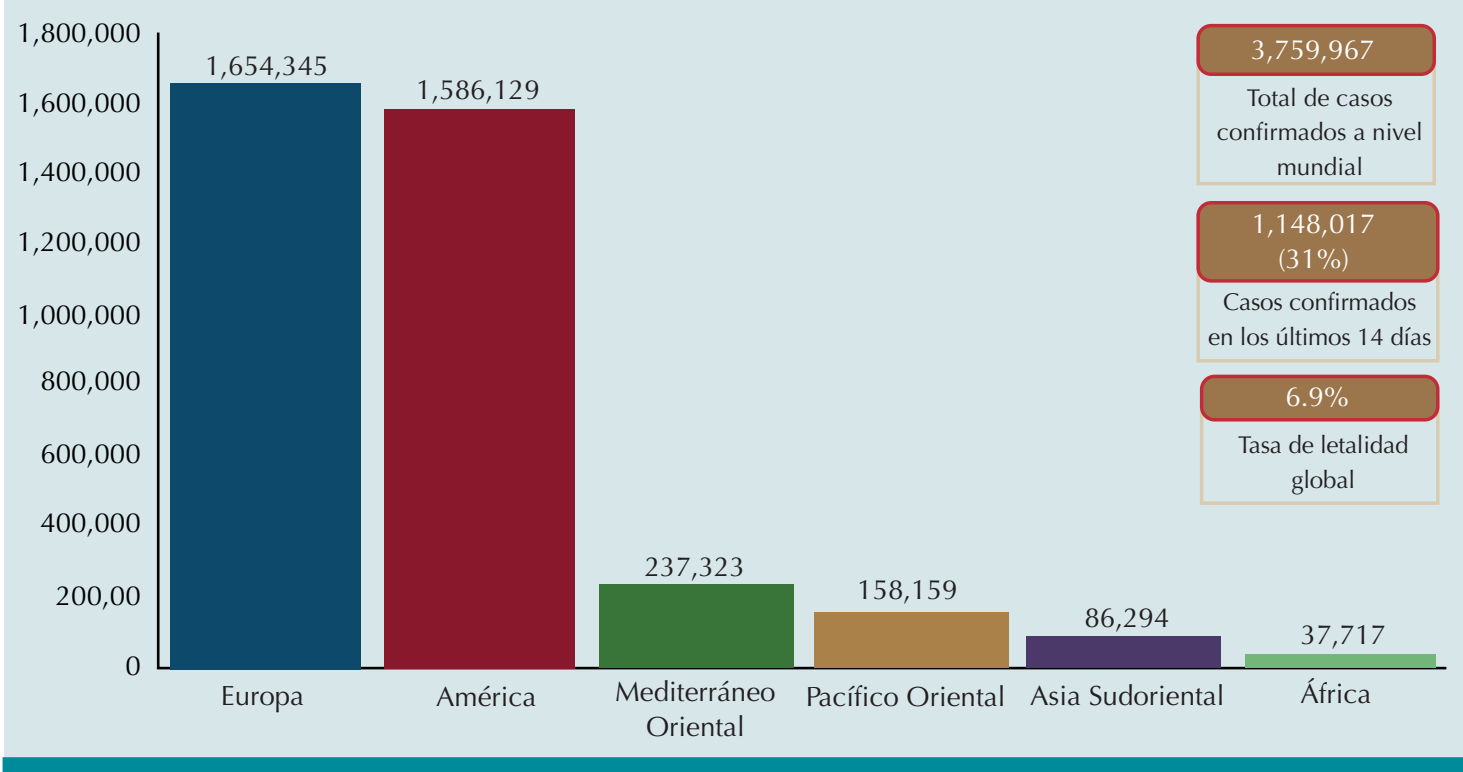

Figura 2. Distribución de casos acumulados de COVID-19 por SARS-CoV-2 por regiones de la OMS. Fuente: https://google.com/coronavirus-map/?hl=es\&nv3=true 


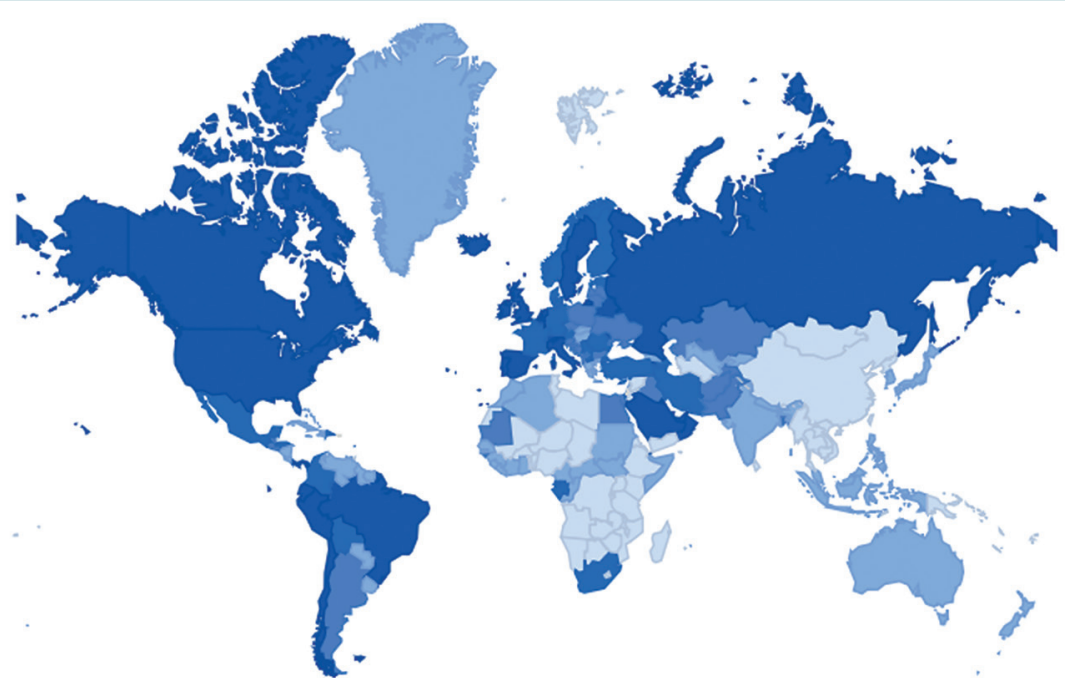

\section{Casos por 1 mill. de personas}

\begin{tabular}{|c|c|c|c|c|}
\hline $0-99$ & $100-499$ & $500-999$ & $1.000-2.499$ & $2.500+$ \\
\hline
\end{tabular}

Figura 3. Mapa mundial de casos COVID-19.

Fuente: Mapa de la enfermedad por coronavirus (COVID-19). https://google.com/coronavirus-map/?hl=es\&nv3=true

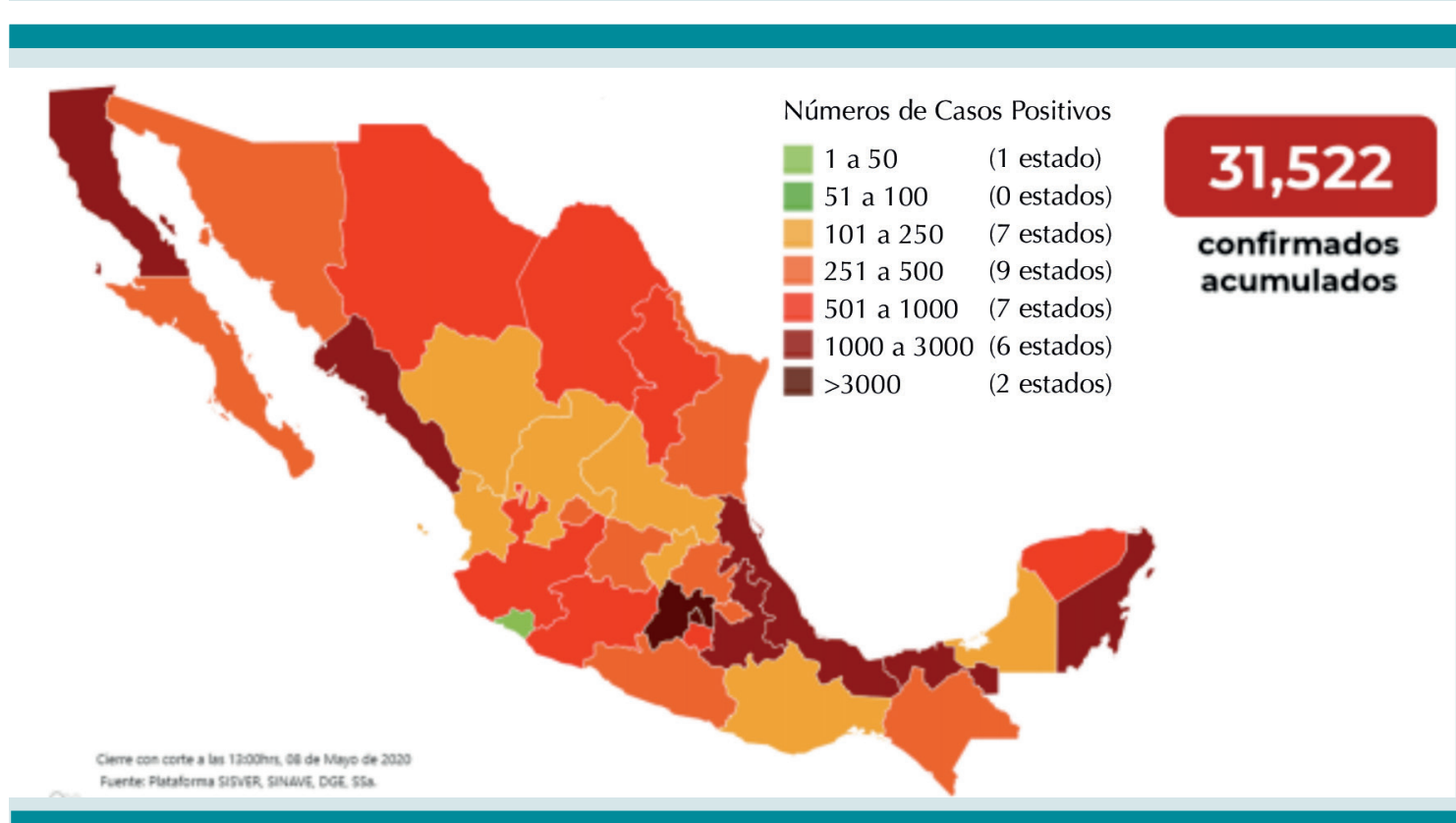

Figura 4. Casos confirmados en México.

Fuente: Secretaría de Salud. Dirección General de Epidemiología. Comunicado Técnico Diario COVID-19 MÉXICO 08/05/2020. https://www.gob.mx/cms/uploads/attachment/file/551316/Comunicado_Tecnico_Diario_COVID-19_2020.05.08.pdf0 
con un caso confirmado o en investigación de COVID-19, o b) viaje o estancia a países con trasmisión local comunitaria* de COVID-19. $\left({ }^{*}\right.$ China, Hong Kong, Corea del Sur, Japón, Italia, Irán, Singapur, España, Francia, Alemania y los siguientes estados de los Estados Unidos: Washington, California y Nueva York).

Caso confirmado: persona que cumpla con la definición operacional de caso sospechoso y que cuente con diagnóstico confirmado por la Red Nacional de Laboratorios de Salud Pública reconocidos por el InDRE. ${ }^{4}$

En el aviso epidemiológico emitido por la Dirección General de Epidemiología el 6 de abril de 2020 se estableció que la vigilancia epidemiológica de COVID-19 cambiaría de modelo a partir de la instrumentación de la nueva definición operacional, para que fuera centinela en las unidades activas para SISVEFLU (cambió de nombre a Sistema de Vigilancia Epidemiológica de Enfermedad Respiratoria Viral, SISVER) y en donde no solo se vigilaría COVID-19, sino también influenza y otros virus respiratorios, manteniendo la vigilancia epidemiológica con pruebas de laboratorio con una proporción de muestreo de $10 \%$ * para los casos ambulatorios (enfermedad respiratoria viral) y $100 \%$ para los casos graves hospitalizados (IRAG).

Fue así como días después comenzó a aplicarse la nueva definición de caso:

Caso sospechoso: persona de cualquier edad que en los últimos 7 días haya tenido, al menos, dos de los siguientes signos y síntomas: tos, fiebre o cefalea* acompañados de al menos uno de los siguientes signos o síntomas:

- Disnea (dato de gravedad)

- Artralgias
- Mialgias

- Odinofagia-ardor faríngeo

- Rinorrea

- Conjuntivitis

- Dolor torácico

*En menores de cinco años la irritabilidad puede sustituir a la cefalea.

Caso de infección respiratoria aguda grave: toda persona que cumpla con la definición de caso sospechoso de enfermedad respiratoria leve y, además, tenga dificultad para respirar y esté hospitalizado.

Caso confirmado: persona que cumpla con la definición operacional de caso sospechoso y que cuente con diagnóstico confirmado por laboratorio de la Red Nacional de Laboratorios de Salud Pública reconocidos por el InDRE.**5

\section{CONCLUSIONES}

De acuerdo con la OMS, se denomina pandemia a la propagación mundial de una nueva enfermedad. El SARS-COV-2, al igual que todas las pandemias que han marcado la historia de la humanidad, ha causado estragos en todos niveles pero, sin duda, ha mostrado cómo un virus puede ocasionar cambios drásticos en la forma de vida y convivencia del ser humano, cómo la salud es y será siempre prioridad en todos los ámbitos.

La superación de esta pandemia dependerá, en su mayor parte, de la disciplina que la población mundial tenga para respetar las reglas de convivencia-distanciamiento social y, la única y mejor medida de prevención de casos en futuras temporadas será mantener la guardia y no dejar de aplicar las medidas de prevención sugeridas: etiqueta respiratoria, aislamiento físico ante la 
aparición de síntomas respiratorios, solicitud de atención médica oportuna, uso de equipo de protección personal adecuado en caso de tener síntomas respiratorios, respetar las reglas de convivencia social ante la existencia de casos, higiene de manos constante y correcta, y todas las nuevas recomendaciones que, a lo largo de esta pandemia, muestren ser efectivas para la prevención y control de casos.

\section{REFERENCIAS}

1. Organización Mundial de la Salud. Cronología de la actuación de la OMS: https://www.who.int/es/news-room/ detail/27-04-2020-who-timeline---covid-19.
2. Organización Mundial de la Salud. Declaración de la segunda reunión del Comité de Emergencias del Reglamento Sanitario IInternacional (2005) acerca del brote del nuevo coronavirus (2019-nCoV). [En línea] 30 de enero de 2020 https://www.who.int/es/news-room/detail/30-01-2020-statement-on-the-second-meeting-of-the-international-healthregulations-(2005)-emergency-committee-regarding-theoutbreak-of-novel-coronavirus-(2019-ncov).

3. Organización Panamericana de la Salud. Actualización Epidemiológica Nuevo coronavirus (COVID-19). Obtenido de https://www.paho.org/sites/default/files/2020-02/2020feb-28-phe-actualizacion-epi-covid19.pdf.

4. Dirección General de Epidemiología, SS. Aviso Epidemiológico CONAVE /01/ 2020/2019-nCoV. https://www.gob.mx/ cms/uploads/attachment/file/527027/AE-Nuevo_Coronavirus_2019_nCoV.pdf.

5. Secretaría de Salud: Aviso Epidemiológico CONAVE /09/ 2020/COVID-19. https://www.gob.mx/cms/uploads/ attachment/file/545445/AE_Enfermedad_COVID-19_SARSCoV-2_2020.04.06.pdf. 